\title{
Implications of Antidepressants Use in Breast Cancer: A Brief Review
}

\author{
Angela Strazzanti ${ }^{1}$, Federica Martorana ${ }^{2}$, Eva Intagliata ${ }^{1^{*}}$, Katia Lanzafame ${ }^{2}$, Giuliana Pavone ${ }^{2}$, \\ Sergi Mauro ${ }^{1}$, Gangi Santi ${ }^{1}$, Livia Manzella ${ }^{3}$, Francesco Basile ${ }^{1}$, Claudio Trovato ${ }^{1}$
}

'Department of General Surgery and Senology, A.O.U. Policlinico Vittorio Emanuele, Catania, Italy ${ }^{2}$ Division of Medical Oncology, A.O.U. Policlinico-Vittorio Emanuele, Catania, Italy

${ }^{3}$ Department of Clinical and Experimental Medicine, University of Catania, Italy

\author{
*Corresponding author: \\ Eva Intagliata, MD PhD \\ Division of Medical Oncology \\ University of Catania, Italy \\ Policlinico Vittorio Emanuele Hospital \\ Via S. Sofia 78, 95123 Catania, Italy \\ Tel: 00393470674195 \\ E-mail: evaintagliata@vodafone.it
}

\section{ABSTRACT}

We review herein the available data regarding the potential relationship between antidepressants and breast cancer. According to some studies, the biological rationale leading correlation among antidepressants and mammary carcinogenesis is represented by the increase in prolactin levels and by the promotion of cell proliferation. However, these studies seem to be spoiled by an unsatisfactory statistical design and by the lack of a good control for confounding elements. Thus, experimental and clinical data remain controversial, even though recent studies tend to exclude a causative link between depressive disorders and breast malignancies. We have also investigated whether the concomitant use of selective serotonin re-uptake inhibitors and hormonal therapy influences cancer-related risk of death in ER-positive breast cancer patients treated with adjuvant anti-estrogen therapy. Even here an unequivocal consensus seems to be lacking, most of the studies suggest that women in hormonal adjuvant therapy experiencing depression can be safely treated with SSRI, without a negative impact on breast cancer prognosis. Whether depression and antidepressant have a role in breast tumour development, a reverse correlation is undeniably present. We reviewed the Literature to assess if there is a relationship between antidepressants and breast cancer risk and if antidepressants use may affect breast cancer patients' prognosis. We also provide a thorough list of potential pharmacological interactions between the molecules currently used for breast cancer treatment and antidepressants.

Key words: breast cancer, depression, antidepressants, drugs interactions

\section{INTRODUCTION}

The potential relationship between depression and breast cancer has been extensively explored over the last decades. The assumed biological rationale behind this association leans to an intricate network involving the nervous, immune and endocrine system (1). In fact, reduced cytotoxic T lymphocytes, Natural Killers and inflammatory cytokines activity, along with higher cortisol levels typically associated with depression, may represent a proliferative drive for cancer cells. Experimental and clinical data remain controversial, even though recent studies tend to exclude a causative link between depressive disorders and breast malignancies (2). 
Similarly, a correlation between antidepressants and breast cancer has been postulated. Researches mainly focused on Selective Serotonin Re-uptake Inhibitors (SSRI), the most prescribed antidepressant category, which increase circulating prolactin (PRL) levels, thus stimulating cell proliferation, differentiation and angiogenesis, finally leading to an increased risk of breast cancer. Again, several controversial findings made this hypothesis unclear. Moreover, many studies investigated antidepressants influence on breast cancer recurrence and survival (3).

Whether depression and antidepressant may have a role in breast tumour development, a reverse correlation between these entities is undeniably present, since a cancer diagnosis represents a major risk of moodrelated disorders. Therefore, given the progressively increasing amount of women diagnosed with breast cancer, every oncologist should be aware of the potential drug-to-drug interactions between antidepressants and antineoplastic agents, and to properly manage them in a multidisciplinary team with neurologist, psychiatrist and psychologist (4-5).

In this paper, we aimed to assess if a relationship between antidepressants and breast cancer risk exist and if antidepressants use may affect breast cancer patients' prognosis. A systematic review of the Literature has been performed by inserting on Pubmed the keywords "breast cancer" AND "antidepressant" AND "depression". Only the more recent and relevant results to our research issue were selected.

We also provide a thorough list of potential pharmacological interactions between the molecules currently used for breast cancer treatment and antidepressants.

\section{DISCUSSION}

During the last decades, a plethora of experimental and epidemiological studies unsuccefully tried to discover a potential pathogenic role between antidepressants and breast cancer.

Antidepressants biological effects may potentially lead to breast cancerogenesis, since all these medications seem to increase circulating PRL levels, hamper the immune system and promoting cell proliferation (6).

However, a growing number of evidences seem to disconfirm that higher PRL levels are associated with breast cancer development in humans $(7,8)$.

Additionally, immune system de-regulation in antidepressants users may occur by enhancing immune cells activity (6).
Fluoxetine treatment increases the number of brain breast cancer metastases in murine model, an effect accompanied by elevated permeability of the bloodbrain barrier, pro-inflammatory changes in the brain, and glial activation. This suggests a possible role of brain-resident immune cells and glia in promoting increased development of brain metastases (9). Raloxifene/Fluoxetine combination had a better effect than Raloxifene or Fluoxetine alone against induced breast cancer in rats and may represent a new therapeutic modality for management of breast cancer (10).

Apart from pre-clinical experiments, a plethora of epidemiologic studies explored whether antidepressants use may increase the risk of breast cancer in the healthy population (11-14) (table 1). No conclusive data are available, and a recent prospective trial conducted on a large cohort of 4014 women both in pre-menopausal and postmenopausal subjects failed to demonstrate this relationship (3).

Scarce evidences exist about antidepressants use and the onset of a specific breast cancer subtype, defined on the basis of hormonal receptors and HER2 status. Two studies did not showed correlation between antidepressants and ER positive breast cancer $(15,16)$, whereas another one reported a significant increase of Estrogen Receptor (ER) positive/ Progesteron Receptor (PR) negative breast tumour risk in patients on SSRIs (17).

Experimental and epidemiological data does not seem to support the hypothesis that antidepressants increase the risk of breast cancer, even though these evidences come from a plethora of studies with satisfactory statistical design, adequate exposure definitions and good control for confounding elements (12). The relationship between breast cancer and antidepressant use needs to be further evaluated.

Several studies investigated whether the concomitant use of SSRI and hormonal therapy influences cancer-related risk of death in early-stage ER-positive breast cancer patients treated with adjuvant antiestrogen therapy (Tamoxifen or aromatase inhibitors).

A large UK cohort trial conducted on 23.669 breast cancer patients found a $27 \%$ increase of breast cancer mortality in women taking SSRIs. SSRIs users had a higher breast cancer-specific mortality than non-users with no apparent dose-response relationship. Nonetheless, data are lacking about patients' adherence to SSRI and anti-cancer treatment (1).

An adherence study and a nested case-control study considered Swedish women who were diagnosed with ER-positive breast cancer from July 2007 and July 2011. 
Table 1 - Studies about association between ADs use and breast cancer risk

\begin{tabular}{|c|c|c|c|}
\hline Study & Study characteristics & No of cases/controls & Results \\
\hline Cotterchio et al.(5) & $\begin{array}{l}\text { Population-based Case-Control study } \\
\text { 1995-1996 } \\
\text { Canada }\end{array}$ & $\begin{array}{l}750 \text { cases } \\
750 \text { controls }\end{array}$ & $\begin{array}{l}\text { ADs not associated with } \\
\text { increased breast cancer risk }\end{array}$ \\
\hline Ikuko Kato et al. (6) & $\begin{array}{l}\text { Cohort study } \\
1985-1991 \\
\text { New York and Florida }\end{array}$ & $\begin{array}{l}566 \text { breast cancer cases } \\
\text { total population } 15270 \text { cases }\end{array}$ & $\begin{array}{l}\text { ADs associated with increased } \\
\text { breast cancer risk }\end{array}$ \\
\hline Wang et al.(7) & $\begin{array}{l}\text { Retrospective Cohort study } \\
1989-1996 \\
\text { USA }\end{array}$ & $\begin{array}{l}571 \text { breast cancer cases } \\
38273 \text { ADs users } \\
32949 \text { ADs nonusers }\end{array}$ & $\begin{array}{l}\text { ADs associated with increased } \\
\text { breast cancer risk }\end{array}$ \\
\hline Moorman et al. (8) & $\begin{array}{l}\text { Population-based Case-Control study } \\
1993-2000 \\
\text { USA }\end{array}$ & $\begin{array}{l}938 \text { cases } \\
771 \text { controls }\end{array}$ & $\begin{array}{l}\text { ADs not associated with } \\
\text { increased breast cancer risk }\end{array}$ \\
\hline Coogan et al. (9) & $\begin{array}{l}\text { Hospital-based Case Control study } \\
1988-2002 \\
\text { USA }\end{array}$ & $\begin{array}{l}2138 \text { cases } \\
2858 \text { controls }\end{array}$ & $\begin{array}{l}\text { ADs not associated with } \\
\text { increased breast cancer risk }\end{array}$ \\
\hline Gonzalez-Perez et al. (10) & $\begin{array}{l}\text { Registry-based Nested Case-Control study } \\
\text { 1995-2001 } \\
\text { UK }\end{array}$ & $\begin{array}{l}3708 \text { cases } \\
20000 \text { controls }\end{array}$ & $\begin{array}{l}\text { ADs not associated with } \\
\text { increased breast cancer risk }\end{array}$ \\
\hline Chien et al. (11) & $\begin{array}{l}\text { Population-based Case-Control study } \\
\text { 1997-1999 } \\
\text { Location: USA }\end{array}$ & $\begin{array}{l}975 \text { cases } \\
1007 \text { controls }\end{array}$ & $\begin{array}{l}\text { ADs not associated with } \\
\text { increased breast cancer risk }\end{array}$ \\
\hline Wernli et al. (12) & $\begin{array}{l}\text { Population-based Case-Control study } \\
\text { 2003-2006 } \\
\text { USA }\end{array}$ & $\begin{array}{l}2908 \text { cases } \\
2927 \text { controls }\end{array}$ & $\begin{array}{l}\text { ADs not associated with } \\
\text { increased breast cancer risk }\end{array}$ \\
\hline Haukka et al. (13) & $\begin{array}{l}\text { Registry-based Cohort study } \\
\text { 1998-2005 } \\
\text { USA }\end{array}$ & $\begin{array}{l}1365 \text { cases } \\
418588 \text { controls }\end{array}$ & $\begin{array}{l}\text { ADs associated with increased } \\
\text { breast cancer risk }\end{array}$ \\
\hline Ashbury et al. (14) & $\begin{array}{l}\text { Registry-based Nested Case-Control study } \\
2003-2006 \\
\text { Canada }\end{array}$ & $\begin{array}{l}1701 \text { cases } \\
17017 \text { controls }\end{array}$ & $\begin{array}{l}\text { ADs not associated with } \\
\text { increased breast cancer risk }\end{array}$ \\
\hline Walker et al. (15) & $\begin{array}{l}\text { Registry-based Case Control } \\
\text { UK }\end{array}$ & $\begin{array}{l}1642 \text { cases } \\
3262 \text { controls }\end{array}$ & $\begin{array}{l}\text { ADs not associated with } \\
\text { increased breast cancer risk }\end{array}$ \\
\hline
\end{tabular}

The adherence study, conducted on 9104 patients, demonstrated that short-term SSRIs users (3-18 months) were less compliant to endocrine therapy than long-term SSRIs users ( $\geq 18$ months). In the nested casecontrol study, 445 cases (breast cancer deaths) and 11.125 controls (25 for each case) were included. The endpoint study was the odds ratio of breast cancer death in relation to short-term and long-term SSRIs exposure. No association between concomitant use of SSRIs and oral hormone therapy and breast cancerspecific survival emerged. In particular, no difference was observed between long-term SSRI users and nonusers, whereas patients with concomitant short-term SSRI use had a worse breast cancer survival than nonusers. However, the poor adherence to endocrine therapy was clearly associated with worse prognosis. These results underline the importance of a proper management of depressed breast cancer patients in order to improve their compliance towards both antidepressants and anti-cancer treatment (4).

Additionally, a cohort study conducted on women with early breast cancer diagnosed in Denmark from 1998 to 2011 demonstrated that treatment with antidepressants had significantly increased risk of receiving non-guideline therapy for breast cancer and significantly worse overall survival including breast cancer-specific survival. Of the 45.352 recruited women, 744 (2\%) had a previous hospital contact for depression and 6068 (13\%) had been treated with antidepressants before cancer diagnosis. However, the survival of women with and without previous depression overlapped in both groups, if women with depression received adjuvant treatment according to guidelines. But worse prognosis had those given antidepressants before breast cancer due to the risk of not receiving the standard adjuvant therapy (13). 
Table 2 - Interactions between ADs and drugs used in hormone-receptor positive/HER2 negative breast cancer. Green tiles: no interaction; Yellow tiles: potential interaction; Red tiles: major interaction. TAM Tamoxifen; LETRO Letrozole; ANA: Anastrozole; FULV: Fulvestrant; PALB: Palbociclib; RIB: Ribociclib.

\begin{tabular}{|c|c|c|c|c|c|c|c|c|}
\hline DRUG NAME & TAM & LETRO & ANA & EXE & FULV & EVE & PALB & RIB \\
\hline Imipramine & & & & & & & & \\
\hline Clomipramine & & & & & & & & \\
\hline Trimipramine & & & & & & & & \\
\hline Amitriptyline & & & & & & & & \\
\hline Nortriptyline & & & & & & & & \\
\hline Maprotiline & & & & & & & & \\
\hline Fluoxetine & & & & & & & & \\
\hline Citalopram & & & & & & & & \\
\hline Paroxetine & & & & & & & & \\
\hline Sertraline & & & & & & & & \\
\hline Escitalopram & & & & & & & & \\
\hline Mianserine & & & & & & & & \\
\hline Trazodone & & & & & & & & \\
\hline Nefazodone & & & & & & & & \\
\hline Mirtazapine & & & & & & & & \\
\hline Venlafaxine & & & & & & & & \\
\hline Reboxetina & & & & & & & & \\
\hline Duloxetine & & & & & & & & \\
\hline Agomelatina & & & & & & & & \\
\hline Hypericum & & & & & & & & \\
\hline Vortioxetina & & & & & & & & \\
\hline Selegiline & & & & & & & & \\
\hline
\end{tabular}

Despite univocal consensus is lacking, most of the abovementioned studies suggest that women on hormonal adjuvant therapy experiencing depression can be treated with SSRI without a negative impact on breast cancer prognosis. No data currently support the hypothesis that antidepressants may affect breast cancer patients' outcome.

The potential drug-to-drug interactions between the molecules currently approved for the treatment of breast cancer and the most prescribed anti-depressants are depicted in tables 2-4.

Drugs used for the management of hormone receptor positive breast cancer are those displaying more interactions with antidepressants. Specifically, the selective estrogenic receptor modulator Tamoxifen seriously interacts with 9 of the considered antidepressants, of which 5 are SSRIs (Fluoxetine, Citalopram, Paroxetine, Sertraline and Escitalopram), 2 are
Serotonin and Noradrenalin Reuptake Inhibitors (SNRIs) (Venlafaxin and Duloxetin), one is a serotonin $\mathrm{H} 2$ receptor inhibitor (Nefazodone) and one is the herbal medication Hypericum perforatum.

Tamoxifen undergoes an extensive hepatic metabolism, involving mainly 2D6 cytocrome 450 (CYP2D6), which transform the drug in its active metabolite Endoxifen $(14,18)$. Since SSRIs inhibits CYP2D6, their coadministration with tamoxifen may decrease circulating Endoxifen levels, thus hampering anti-cancer efficacy of the drug. This drug-to-drug interaction may especially occur when tamoxifen is used along with strong or moderate CYP2D6 inhibitors; such are fluoxetine, paroxetine, sertraline and duloxetine (19). Additionally, a slight increase of tamoxifen-induced QT interval prolongation exists when the drug is co-administered with citalopram, escitalopram and venlafaxine $(20,21)$. CYP3A4 plays also a role in early stages of hepatic 
Table 3 - Interactions between ADs and drugs used in HER2 positive breast cancer. Green tiles: no interaction; Yellow tiles: potential interaction; Red tiles: major interaction. TRAST Trastuzumab; PERT: Pertuzumab; LAP: Lapatinib.

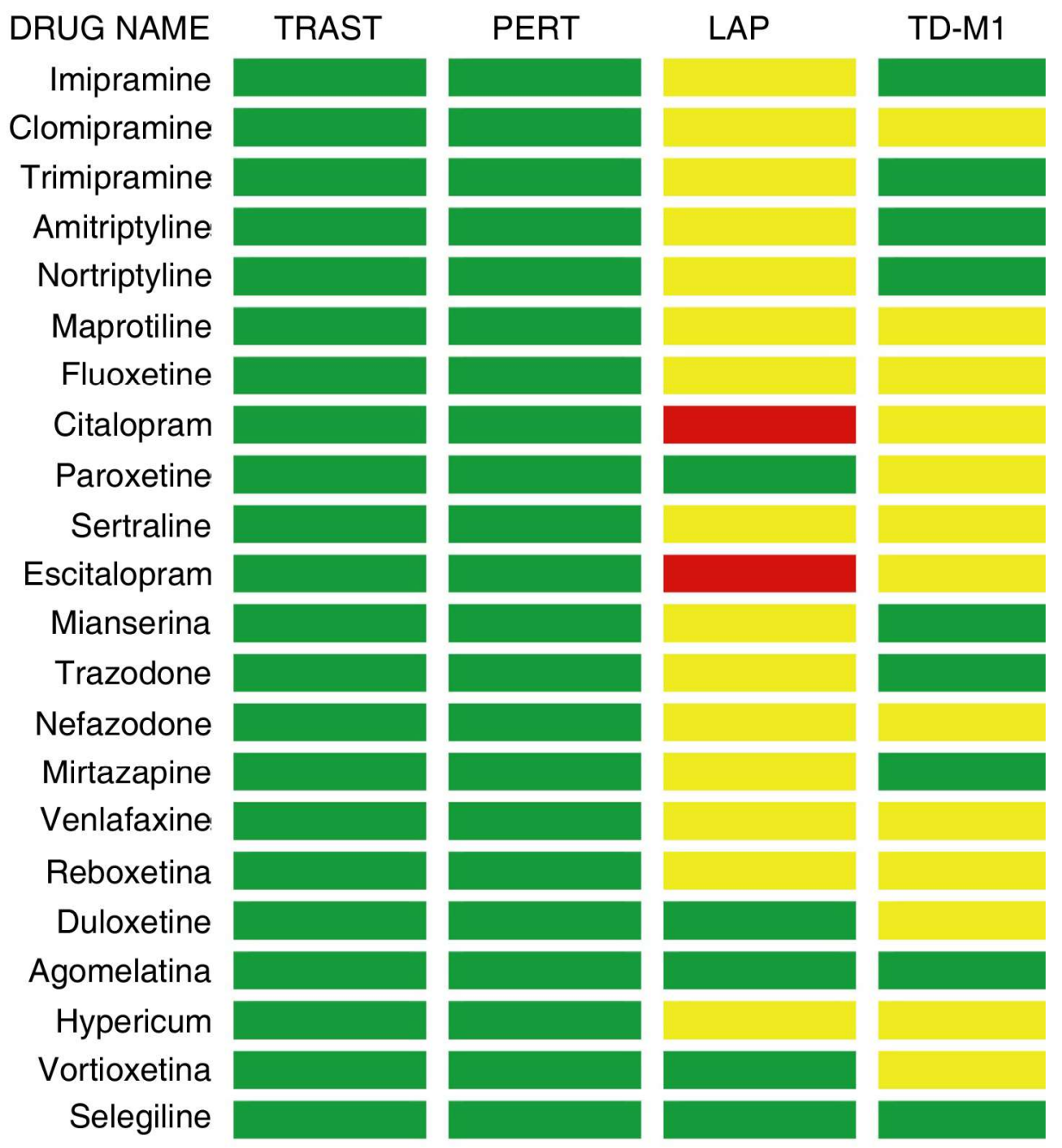

tamoxifen metabolism. Both Nefazodone and Hypericum may affect tamoxifen circulating levels, by inhibiting or inducing CYP3A4, respectively $(22,23)$. However, the CDK4/6 inhibitor Ribociclib, displays 6 major interactions. As for tamoxifen, a QT interval prolongation potentially resulting in "torsade de point" represents the main concern for the concomitant use of Ribociclib and antidepressants (24).

Amongst targeted drugs for HER2 positive breast cancer treatment, the receptor tyrosin-kinase Lapatinib presents interactions with Citalopram and Escitalopram, leading to possible heart toxicity (25). Despite several potential interactions, we have not found any major interaction between the antibodydrug conjugate Trastuzumab Emtansine (TD-M1) and antidepressants. Additionally, anti-HER2 monoclonal antibodies (Trastuzumab and Pertuzumab) have an excellent interaction profile with the given antidepressants. Except for antracyclines and Eribulin melisate, both interacting with Citalopram and Escitalopram with increased risk of cardiotoxicity, the other chemotherapeutic agents commonly employed for the treatment of breast cancer, can be safely administered with anti-depressants $(26,27)$.

Given the high rate of mood disorders amongst cancer patients, the oncologists should be aware of the potential correlation between these diseases and of the pharmacologic interactions, should gain awareness of the potential drug-to-drug interactions which may hamper anticancer treatment efficacy or significantly increase their toxicities, and should manage breast cancer patients with a multi-modal approach that involves the surgeon and a dedicated psychiatrist / psychologist. 
Table 4 - Interactions between ADs and chemotherapeutic agents.

Green tiles tiles: potential interaction; Red tiles: major interaction: ANTR: Antracyclines; TAX: Taxanes; CYCLO: Cyclofosfamide; MTX: Metotrecate; 5-FU: 5-Fluorouracil; CAPE: Capecitabine; VNB: Vinorelbine; EM: Eribulin mesilate.

\begin{tabular}{|c|c|c|c|c|c|c|c|c|}
\hline & ANTR $^{*}$ & $\mathrm{TAX}^{* *}$ & CYCLO & MTX & $5-\mathrm{FU}$ & CAPE & VNB & EM \\
\hline \multicolumn{9}{|l|}{ Imipramine } \\
\hline \multicolumn{9}{|l|}{ Clomipramine } \\
\hline \multicolumn{9}{|l|}{ Trimipramine: } \\
\hline \multicolumn{9}{|l|}{ Amitriptyline } \\
\hline \multicolumn{9}{|l|}{ Nortriptyline } \\
\hline \multicolumn{9}{|l|}{ Maprotiline } \\
\hline \multicolumn{9}{|l|}{ Fluoxetine } \\
\hline \multicolumn{9}{|l|}{ Citalopram } \\
\hline \multicolumn{9}{|l|}{ Paroxetine } \\
\hline \multicolumn{9}{|l|}{ Sertraline } \\
\hline \multicolumn{9}{|l|}{ Escitalopram } \\
\hline \multicolumn{9}{|l|}{ Mianserina } \\
\hline \multicolumn{9}{|l|}{ Trazodone } \\
\hline \multicolumn{9}{|l|}{ Nefazodone } \\
\hline \multicolumn{9}{|l|}{ Mirtazapine } \\
\hline \multicolumn{9}{|l|}{ Venlafaxine } \\
\hline \multicolumn{9}{|l|}{ Reboxetina } \\
\hline \multicolumn{9}{|l|}{ Duloxetine } \\
\hline \multicolumn{9}{|l|}{ Agomelatina } \\
\hline \multicolumn{9}{|l|}{ Hypericum } \\
\hline Vortioxepina & & & & & & & & \\
\hline Selegiline & & & & & & & & \\
\hline
\end{tabular}

\section{Conflicts of Interest and Source of Funding}

The authors have neither conflicts of interest nor source of funding to disclose.

\section{REFERENCES}

1. Busby J, Mills K, Zhang SD, Liberante FG, Cardwell CR. Selective serotonin reuptake inhibitor use and breast cancer survival: a population-based cohort study. Breast Cancer Res. 2018;;20(1):4.

2. Eom Cs, Park Sm, Cho KH. Use of antidepressants and the risk of breast cancer: a meta-analysis. Breast Cancer Res Treat. 2012; 136(3):635-45.

3. Reeves Kw, Okereke Oi, Qian J, Tamimi RM, Eliassen AH, Hankinson SE. Depression, Antidepressant Use, and Breast Cancer Risk in Preand Postmenopausal Women: A Prospective Cohort Study. Cancer Epidemiol Biomarkers Prev. 2018;;27(3):306-314.

4. Valachis A, Garmo H, Weinman J, Fredriksson I, Ahlgren J, Sund M, Holmberg L. Effect of selective serotonin reuptake inhibitors use on endocrine therapy adherence and breast cancer mortality: a population-based study. Breast Cancer Res Treat. 2016;159(2):293-303.
5. Chubak J, Bowles EJ, Yu O, Buist DS, Fujii M, Boudreau DM. Breast Cancer Recurrence In Relation To Antidepressant Use. Cancer Causes Control. 2016;;27(1):125-36.

6. Hong R, Zhou Y, Tian X, Wang L, Wu X. Selective inhibition of ID01, D-1-methyl-tryptophan (D-1MT), effectively increased EpCAM/CD3bispecific BiTE antibody MT110 efficacy against ID01hibreast cancer via enhancing immune cells activity. Int Immunopharmacol. 2018:54:118-124. Epub 2017 Nov 9.

7. Motamedi B, Rafiee-Pour HA, Khosravi MR, Kefayat A, Baradaran A, Amjadi E, Goli P. Prolactin receptor expression as a novel prognostic biomarker for triple negative breast cancer patients. Ann Diagn Pathol. 2020:46:151507.

8. Hachim IY, Hachim MY, Lopez VM, Lebrun JJ, Ali S. Prolactin Receptor Expression is an Independent Favorable Prognostic Marker in Human Breast Cancer. Appl Immunohistochem Mol Morphol 2016;24(4):238-45.

9. Shapovalov Y, Zettel M, Spielman SC, Amico-Ruvio SA, Kelly EA, Sipe G0, Dickerson IM, Majewska AK, Brown EB. Fluoxetine modulates breast cancer metastasis to the brain in a murine model. BMC Cancer. 2014;14:598.

10. Kabel AM, Elkhoely AA. Ameliorative potential of fluoxetine/ raloxifene combination on experimentally induced breast cancer. Tissue Cell. 2016;48(2):89-95. 
11. Tworoger SS, Eliassen AH, Rosner B, Sluss P, Hankinson SE. Plasma prolactin concentrations and risk of postmeno- pausal breast cancer Cancer Res. 2004;64(18):6814-9.

12. Coogan PF. Review of the epidemiological literature on antidepressant use and breast cancer risk. Expert Rev Neurother. 2006; $6(9): 1363-74$.

13. Suppli NP, Johansen C, Kessing LB, Toender A, Kroman N, Ewertz M, Dalton SO. Survival after early-stage breast cancer of women previously treated for depression: a nationwide Danish cohort study. J Clin Oncol. 2017;35(3):334-342.

14. Crewe HK, Ellis SW, Lennard MS, Tucker GT. Variable contribution of cytochromes P450 2D6, 2C9 and 3A4 to the 4-hydroxylation of tamoxifen by human liver microsomes. Biochem Pharmacol. 1997; 53(2):171-8.

15. Coogan PF, Strom BL, Rosenberg L. SSRI use and breast cancer risk by hormone receptor status. Breast Cancer Res Treat. 2008; 109:527-531.

16. Wang PS, Walker AM, Tsuang MT, Orav EJ, Levin R, Avorn J. Antidepressant use and the risk of breast cancer: a non-association. J Clin Epidemiol. 2001:54(7):728-34.

17. Chien C, Li Cl, Heckbert SR, Malone KE, Boudreau DM, Daling JR Antidepressant use and breast cancer risk. Breast Cancer Res Treat 2006;95:131-140.

18. Desta Z, Ward BA, Soukhoba NV. Comprehensive evaluation of tamoxifen sequential biotransformation by the human cytochrome P450 system in vitro: prominent roles for CYP3A and CYP2D6. J Pharmacol Exp Ther. 2004;310(3):1062-75.

19. Del Re M, Citi V, Crucitta S, Rofi E, Belcari F, van Schaik RH, et al. Pharmacogenetics of CYP2D6 and tamoxifen therapy: Light at the end of the tunnel? Pharmacol Res. 2016:107:398-406.

20. Grouthier V, Lebrun-Vignes V, Glazer AM, Touraine P, FunckBrentano C, Pariente A, et al. Increased long QT and torsade de pointes reporting on tamoxifen compared with aromatase inhibitors. Heart. 2018;Nov;104(22):1859-1863.

21. Beach SR, Kostis WJ, Celano CM, Januzzi JL, Ruskin JN, Noseworthy PA, et al. Meta-analysis of selective serotonin reuptake inhibitor-associated QTc prolongation. J Clin Psychiatry. 2014; 75(5):e441-9.

22. Lam YW, Alfaro CL, Ereshefsky L, Miller M. Pharmacokinetic and pharmacodynamic interactions of oral midazolam with ketoconazole, fluoxetine, fluvoxamine, and nefazodone. J Clin Pharmacol. 2003;43(11):1274-82.

23. Izzo AA, Ernst E. Interactions between herbal medicines and prescribed drugs. Drugs. 2009;69(13):1777-98.

24. Spring LM, Zangardi ML, Moy B, Bardia A. Clinical management of potential toxicities and drug interactions related to cyclin dependent kinase 4/6 inhibitors in breast cancer: practical consideration and recommendation. Oncologist. 2017;22(9):1039-1048.

25. Shah RR, Morganroth J. Update on cardiovascular safety of tyrosine kinase inhibitors: with a special focus on QT interval, left ventricular dysfunction and overall risk/benefit. Drug Saf. 2015;38(8):693-710.

26. Porta-Sánchez A, Gillbert C, Spears D, Amir E, Chan J, Nanthakumar $\mathrm{K}$, et al. Incidence, diagnosis, and management of qt prolongation induced by cancer therapies: a systematic review. J Am Heart Assoc. 2017:6(12):e007724.

27. Shetty N, Gupta S. Eribulin drug review. South Asian J Cancer. 2014; $3(1): 57-9$ 